\title{
Nutrition transition in India
}

\author{
Prakash S Shetty ${ }^{\dagger}$
}

Nutrition Planning, Assessment and Evaluation, Food and Nutrition Division, Food and Agriculture Organization (FAO) of the United Nations, Via delle Terme di Caracalla, I-00100 Rome, Italy

\begin{abstract}
Objective: The primary objective of this review is to examine the demographic and nutrition transition in India in relation to its contribution to the emerging epidemic of chronic non-communicable diseases in this country.

Setting: India, the country as a whole and its different states with a population exceeding 1 billion in 2001.

Subjects: The review examines demographic changes in the population with consequent effects on the population pyramid, the rapidity and rates of urbanisation with striking variations in chronic disease patterns and the trends in obesity between rural and urban communities, attempting to relate their prevalence with the diet and lifestyle changes accompanying them.

Design: The review is based largely on representative large-scale surveys in the country and other reliable documented data on population characteristics. It also includes a review of the published literature.

Results: The results indicate that the demographic changes, rates of urbanisation and changes in dietary patterns are contributing to the changing trends in chronic disease in India.

Conclusions: There is clear evidence of a demographic, epidemiological and nutrition transition in India that is fuelling the epidemic of chronic diseases and obesity, particularly in the urban areas.
\end{abstract}

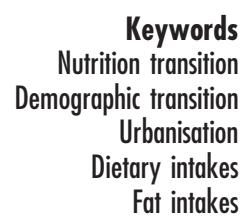

A recent analysis of mortality trends suggests that large increases in non-communicable diseases (NCDs) have occurred in developing countries ${ }^{1}$, particularly those in rapid transition (e.g. Brazil, China and India). According to these estimates, at least $40 \%$ of all deaths in developing countries are attributable to NCDs (vs. $75 \%$ in industrialised countries). The rapid increase in these diseases is found disproportionately in poor and disadvantaged populations of low- and middle-income countries and is contributing to widening health gaps between and within countries. In $1998,77 \%$ of the total number of deaths attributable to NCDs occurred in developing countries, and $85 \%$ of the disease burden was borne by low- and middle-income countries ${ }^{2}$. The complex range of factors that interact to determine the nature and course of this epidemic needs to be understood in order to adopt preventive strategies to help developing societies like India deal with this burgeoning problem ${ }^{3}$. Dietary deficits and excesses - and the lifestyle changes that accompany industrialisation and urbanisation with economic development - make a significant contribution to this epidemic. In this brief overview some of the crucial contributors to the nutrition transition in India, which are important

tFormerly with the Public Health Nutrition Unit, Department of Epidemiology and Population Health, London School of Hygiene and Tropical Medicine, UK. determinants of the burgeoning problem of NCDs in this country, will be reviewed.

\section{Demographic and epidemiological transitions in India}

India is in the phase of a rapid demographic transition. Life expectancy is increasing while birth rates are on the decline. The share of the population above 60 years of age is growing at a rapid rate and is expected to exceed 200 million in 25 years. Those who cross the age of 60 today are expected to live up to or over the age of 75 years. The following estimates are indicative of the changes expected in India's population:

1. the total population will rise from 846.2 million in 1991 to 1263 million in 2016 (49\% increase) and to 1.33 billion in 2026 ( $57 \%$ increase);

2. the population over 60 years old will rise from 54.7 million in 1991 to 113.0 million in 2016 (107\% increase) or from $6.4 \%$ of the population to $8.9 \%$; it will increase further to 179 million in 2026 (227\% increase); and

3 . the aged population (over 60 years) will constitute $13.3 \%$ of the 1333 million total population in 2026.

However, the population growth rate is not uniform in all states or regions of the country. Table $1^{4,5}$ illustrates the demographic transition in the major Indian states. Kerala 
Table 1 Demographic transition in major Indian states: status and projection

\begin{tabular}{lcccc}
\hline State & $\begin{array}{c}\text { State population } \\
\text { in 1991 (millions } \\
\text { of people) }\end{array}$ & $\begin{array}{c}\text { Population } \\
\text { annual growth } \\
\text { rate, 1981-91 (\%) }\end{array}$ & $\begin{array}{c}\text { Year by which TFR } \\
\text { declines to 2.1 - the } \\
\text { replacement level }\end{array}$ & $\begin{array}{c}\text { Variation in level } \\
\text { of urbanisation } \\
(\%)\end{array}$ \\
\hline Andhra Pradesh & 66.5 & 2.17 & 2002 & 26.9 \\
Assam & 22.4 & 2.17 & 2015 & - \\
Bihar & 86.4 & 2.11 & 2039 & 13.1 \\
Gujarat & 41.3 & 1.92 & 2014 & 35.5 \\
Haryana & 16.5 & 2.42 & 2025 & 24.6 \\
Himachal Pradesh & 5.2 & 1.89 & 2009 & 8.6 \\
Karnataka & 45.0 & 1.92 & $1988 \dagger$ & 30.9 \\
Kerala & 29.1 & 1.34 & Beyond 2060 & 26.4 \\
Madhya Pradesh & 66.2 & 2.38 & 2008 & 23.2 \\
Maharashtra & 78.9 & 2.29 & 2010 & 38.7 \\
Orissa & 31.7 & 1.83 & 2019 & 13.4 \\
Punjab & 20.3 & 1.99 & $1993 \dagger$ & 29.6 \\
Rajasthan & 44.0 & 2.50 & Beyond 2100 & 22.9 \\
Tamil Nadu & 55.9 & 1.43 & 2009 & 34.2 \\
Uttar Pradesh & 139.1 & 2.27 & 2026 & 19.8 \\
West Bengal & 68.1 & 2.21 & 2.14 & - \\
All India & 846.3 & & 27.5 \\
\hline
\end{tabular}

Source: data in columns 1 to 3 are from the 1991 Census Hand Book; data in column 4 are from Population Projections for India and States 1996-2001, UNDP India ${ }^{5}$; data in column 5 are from the Census of India, $1991^{4}$.

*NA - not available.

† Kerala and Tamil Nadu have already achieved the TFR of 2.1 in 1988 and 1993, respectively.

and Tamil Nadu achieved the Total Fertility Rate (TFR) at the replacement level of 2.1 in 1988 and 1993, respectively. The four states likely to remain above the TFR replacement level well after 2025 are Bihar, Madhya Pradesh, Rajasthan and Uttar Pradesh. While Bihar and Rajasthan are likely to reduce TFR below the replacement level by 2050, Madhya Pradesh is not likely to reach this level before 2060, and Uttar Pradesh not before 2100. India's demographic battle in the 21st century is expected to be fought in these latter states.

Comparison of the age distribution of the population pyramids of China and India suggests that the population increase will continue in India unabated and hence will certainly exceed China's. The population projections made by the Registrar General of India's office (1998) from 1971 to 2001 and projected for the next 15 years (i.e. 2016) indicate that, in the period between 1996 and 2016, the following population changes are expected:

1. the age group $15-59$ years will increase from 519 to 800 million;

2. the age group $<15$ years will decline from 353 to 350 million; while

3. the age group $>60$ years will increase from 62.3 to 112.9 million, clearly indicating that the dependency ratio will continue to decline.

It is important to recognise, however, that changes in the population age pyramid are also highly variable within the country, due to differences in the period of onset of demographic transition and to differences in the rates of transition. A comparison of the differences between the two major states of Kerala and Uttar Pradesh (UP) shows that the population pyramid of Kerala is approaching that of more developed countries while that of UP resembles less developed countries.

Epidemiological transition, on the other hand, focuses on the complex changes in patterns of health, disease and mortality that result from these demographic and associated economic and sociological changes. This health and mortality transition entails substitution of chronic degenerative NCDs for infectious and communicable diseases as the primary causes of morbidity and mortality ${ }^{6}$. Developing countries like India, currently lagging behind those having completed the epidemiological transition, will demonstrate a decline in infectious disease mortality and a rise in NCDs. However, evidence of an epidemiological transition is obvious in India with NCDs contributing increasingly to premature deaths in adults, particularly in the urban areas. Emerging evidence of an important role for infective agents in the development of chronic disease risk $^{7}$ is provided by classical risk factors for diabetes and heart disease being associated with raised concentrations of inflammatory markers. Studies from India support the view that urbanisation increases the levels of cytokines and contributes in some measure to the rural-urban differences in NCD risk ${ }^{8}$.

\section{The impact of urbanisation in India}

Migrant studies enable us to study the interaction between genetic and environmental determinants of NCDs, such as non-insulin-dependent diabetes mellitus (NIDDM), cardiovascular disease and some cancers. Studies of migrants on the one hand demonstrate, for instance, that adoption of the diet, lifestyle patterns and socio-cultural practices of the indigenous population by migrants (i.e. 
Table 2 Urban-rural differences in chronic disease risk in developing societies

\begin{tabular}{lcccc}
\hline & $\begin{array}{c}\text { NIDDM prevalence, } \\
\text { Tamil Nadu } \\
(\%)\end{array}$ & $\begin{array}{c}\text { CHD prevalence, } \\
\text { Delhi } \\
(\%)\end{array}$ & $\begin{array}{c}\text { CHD prevalence, } \\
\text { Moradabad } \\
(\%)\end{array}$ & $\begin{array}{c}\text { Cancer } \\
\text { incidence, Delhi vs. Barshi, } \\
\text { per 100 000 }\end{array}$ \\
\hline $\begin{array}{l}\text { Urban } \\
\text { Rural }\end{array}$ & 8.2 & 9.7 & 9.0 & 118.8 \\
Reference & 2.4 & 2.7 & 3.3 & 57.6 \\
\hline
\end{tabular}

the environment) results in the acquisition of disease patterns similar to those of the native population. On the other hand, studies also provide evidence for the unmasking of a probable genetic predisposition to the risk of early onset adult NCDs following migration and the consequent environmental changes. The best examples are the increased risk of NIDDM and coronary heart disease (CHD) among South Asians (i.e. migrants from the Indian sub-continent to the UK) compared with the native European population?. Plasma cholesterol is one of the strongest predictors of CHD risk within populations and the association between raised plasma cholesterol and CHD among South Asians is just as strong as in Europeans. However, no South Asian community, studied in the UK to date, has average plasma cholesterol levels in middle age higher than the national average in the UK, with no differences in dietary intakes of total and saturated fat ${ }^{10}$. It is likely that the present dietary intakes and lifestyles are probably different from their pre-migration experience and their levels of physical activity may also have altered; changes which may have unmasked a predisposition to these diseases. An ethnic variation in disease risk of migrant populations compared with the native residents or indigenous populations is largely a manifestation of environmental influences that may be contributed by genetic predisposition in these individuals. Similar variations in disease risk are seen within a country or region following internal rural to urban migration. Ruralurban differences in NIDDM and CHD within a region or state in India show variations in disease risk (Table 2) ${ }^{11-14}$, suggesting that internal migration, urbanisation and exposure to changing diet and lifestyles increase the risk of chronic disease ${ }^{3}$.

A major feature of the developmental transition in India is the rapid urbanisation and the large shifts in population from rural to urban areas. Table 3 provides information obtained from the Census of India showing that the process of urbanisation is unrelenting and may exceed $30 \%$ in the 2001 census. The consequences of internal migration and urbanisation in India could be staggering but the problem is likely to be highly variable in different states, given the variations in urban populations between the different states in India (Table 1) and their differential rates of urbanisation.

\section{Obesity and its contribution to NCDs in India}

As developing societies like India industrialise and urbanise, and as standards of living continue to rise, weight gain and obesity are beginning to pose a growing threat to the health of the citizens. According to the World Health Organization's global database ${ }^{15}$, India has a preschool childhood obesity prevalence of about $1 \%$. The use of the commonly used indicator of pre-school childhood malnutrition (weight-for-height) may also exaggerate the problem of obesity among stunted children ${ }^{16}$. Repeated episodes of malnutrition, followed by nutritional rehabilitation, are known to alter body composition and increase the risk of obesity ${ }^{3}$. The discordance between linear growth and adipocyte development will enhance adipocyte development when linear growth is affected by malnutrition. It is likely that these factors will contribute to

Table 3 Trends of urbanisation in India from 1901 to 1991

\begin{tabular}{|c|c|c|c|c|c|c|}
\hline Census year & $\begin{array}{c}\text { Number } \\
\text { of agglomerations/ } \\
\text { cities/towns }\end{array}$ & $\begin{array}{l}\text { Total population } \\
\text { (millions } \\
\text { of people) }\end{array}$ & $\begin{array}{l}\text { Urban population } \\
\text { (millions } \\
\text { of people) }\end{array}$ & $\begin{array}{l}\text { Urban population } \\
\text { as } \% \text { of total } \\
\text { population }\end{array}$ & $\begin{array}{c}\text { Decennial growth } \\
\text { rate of urban population } \\
(\%)\end{array}$ & $\begin{array}{l}\text { Annual } \\
\text { exponential } \\
\text { growth } \\
\text { rate }(\%)\end{array}$ \\
\hline 1901 & 1827 & 238.4 & 25.85 & 10.84 & - & - \\
\hline 1911 & 1815 & 252.1 & 25.94 & 10.29 & 0.35 & 0.03 \\
\hline 1921 & 1949 & 251.3 & 28.09 & 11.18 & 8.27 & 0.79 \\
\hline 1931 & 2072 & 279.0 & 33.46 & 11.99 & 19.12 & 1.75 \\
\hline 1941 & 2250 & 318.7 & 44.15 & 13.86 & 31.97 & 2.77 \\
\hline 1951 & 2843 & 361.1 & 62.44 & 17.29 & 41.42 & 3.47 \\
\hline 1961 & 2365 & 439.3 & 78.94 & 17.97 & 26.41 & 2.34 \\
\hline 1971 & 2590 & 548.2 & 109.14 & 19.91 & 38.23 & 3.21 \\
\hline 1981 & 3378 & 683.3 & 159.46 & 23.34 & 46.14 & 3.83 \\
\hline 1991 & 3768 & 844.3 & 217.18 & 25.72 & 36.19 & 3.09 \\
\hline
\end{tabular}

Source: Census report, $1991^{4}$.

Note: census in 1981 was not conducted in Assam and 1991 census was not held in Jammu and Kashmir. 
Table 4 Distribution of BMI of rural and urban adults of both sexes from a nationally representative survey covering 187 Districts in 18 States $(n=142220$ rural and 35621 urban adults)

\begin{tabular}{lcccc}
\hline \multicolumn{4}{c}{ BMI distribution (\%) } \\
\cline { 2 - 5 } & $<18.5 \mathrm{~kg} \mathrm{~m}^{-2}$ & $18.5-25.0 \mathrm{~kg} \mathrm{~m}^{-2}$ & $25.0-30.0 \mathrm{~kg} \mathrm{~m}^{-2}$ & $>30.0 \mathrm{~kg} \mathrm{~m}^{-2}$ \\
\hline Rural & & & & \\
Men & 29.3 & 66.7 & 3.7 & 0.3 \\
Women & 38.2 & 57.7 & 3.6 & 0.5 \\
Urban & & & 5.4 & 0.4 \\
Men & 38.2 & 68.7 & 5.4 & 0.7 \\
Women & 29.1 & 64.8 & & \\
\hline
\end{tabular}

Source: District Nutrition Profiles Survey 1998, Ministry of Human Resources, Government of India.

increase the problem of obesity given the enormous number of stunted children in India, which is estimated at between $52.0 \%$ and $63.0 \%$ based on three different largescale representative surveys ${ }^{17}$.

Childhood obesity increases the risk of obesity in adulthood and parental obesity interacts quite strongly to alter this risk, and there are several interactive factors contributing to the increased prevalence of obesity in childhood. Societies like India, which are rapidly urbanising, demonstrate increases in energy intake, dramatic increases in fat intake along with increased levels of sedentarianism. Lifestyle changes resulting in physical inactivity and sedentary behaviour are important in contributing to obesity in children. This is exemplified by more time in a day spent by children in physically passive behaviours such as TV viewing, working or playing games on a computer, talking on the telephone, etc.

There are even fewer reliable and representative data on obesity among adults in India ${ }^{15}$. There are, however, several reports from various parts of India, mostly urban, which provide some insight into the problem. A study in Bombay revealed that the prevalence of obesity among young adult males varied from $10.7 \%$ to $53.1 \%{ }^{18}$, while another from urban Delhi, among a large representative sample of 13414 adults (aged 25-64 years), showed an overall prevalence of $27.8 \%{ }^{19}$. The latter study indicated obesity was higher in females $(33.4 \%$ vs. $21.3 \%$ among males) and that obesity was associated with hypercholesterolaemia, hyperlipidaemia and lower levels of physical activity. A more recent report from the Kashmir ${ }^{20}$ of adults over 40 years old, studied by multistage sampling, showed the obesity prevalence to be $15.0 \%$; females having a prevalence of $23.7 \%$ compared with $7.0 \%$ among males. A report from the Nutrition Foundation of India suggests that the prevalence of obesity varies with socio-economic status in urban India ${ }^{21}$, with those in the upper strata having higher prevalence rates (32.2\% among males, 50\% among females) than the middle classes (16.2\% males, $30.3 \%$ females), followed by the lower socio-economic groups (7.0\% males, $27.8 \%$ females) and the poor in urban slums with the lowest (1.0\% males, $4.0 \%$ females). The latter finding shows that India has not yet shown the increase in prevalence of obesity seen among the urban poor that is characteristically observed in Brazil and in South Africa. All of these reports are not truly representative of the problem in the country and unfortunately they used a body mass index (BMI) cut-off of $>25.0 \mathrm{~kg} \mathrm{~m}^{-2}$ that has now been designated as being inclusive of the category of overweight, with frank obesity beginning at a BMI of $30.0 \mathrm{~kg} \mathrm{~m}^{-2}$ and above ${ }^{15}$.

The only representative surveys are the ones conducted by the Food and Nutrition Board (i.e. District Nutrition Profiles survey) $)^{17}$, which have reported prevalences of $0.3 \%$ and $0.7 \%$ in rural and $0.4 \%$ and $0.7 \%$ in urban men and women, respectively, using a BMI cut-off of $>30.0 \mathrm{~kg} \mathrm{~m}^{-2}$ (Table 4). However, the other survey was confined only to women; the National Family Health Survey $^{22}$ showed a prevalence rate of $2.2 \%$ for women aged 15-49 years using $\mathrm{BMI}>30.0 \mathrm{~kg} \mathrm{~m}^{-2}$. It varied depending on residence (urban $=5.8 \%$ vs. rural $=0.9 \%$ ), increasing with educational achievement from $0.9 \%$ for illiterate to $6.5 \%$ for those with secondary education. Thus the true prevalence of obesity in India may be overestimated in the reports published in the literature. However, it is increasingly evident that, in populations from the Indian sub-continent, BMI does not provide a good indicator of body fat (i.e. that body fat content is higher) for any given BMI among Indians ${ }^{23}$. Increasing BMI is associated with central adiposity and higher waist/hip ratios along with risk of NCDs appearing at much lower BMI $\left(<25.0 \mathrm{~kg} \mathrm{~m}^{-2}\right)$ than among other population groups ${ }^{24}$. Hence, the true problem regarding the contribution of obesity to NCDs in India may not be exaggerated by the earlier reports that used BMI $>25.0$ $\mathrm{kg} \mathrm{m}^{-2}$ as the cut-off. Obesity, both in children and adults, and its contribution to NCDs are likely to become a serious health problem in India with economic development and urbanisation altering dietary habits and lifestyle patterns that will promote a positive energy balance when food adequacy is achieved.

\section{Dietary consumption and lifestyle changes during the nutrition transition in India}

These rapid quantitative changes in dietary intake in developing countries indicate an increase in per capita 
Table 5 Consumption of food items (g per consumption unit (CU) per day) and nutrients in rural and urban populations in India between 1970 s and 1990s. In addition to time trends the data on urban populations show differences between socio-economic classes

\begin{tabular}{|c|c|c|c|c|c|c|c|c|}
\hline & \multicolumn{4}{|c|}{$\begin{array}{l}\text { Rural consumption } \\
\text { of food items ( } \mathrm{g} \text { per CU per day) }\end{array}$} & \multicolumn{4}{|c|}{$\begin{array}{l}\text { Urban consumption } \\
\text { of food items (g per CU per day) }\end{array}$} \\
\hline & $1975-79$ & $1988-90$ & $1990-91$ & 1995 & $\begin{array}{c}1975-79 \\
\text { Middle class }\end{array}$ & $\begin{array}{l}1975-79 \\
\text { Slums }\end{array}$ & $\begin{array}{c}1995 \\
\text { Middle class }\end{array}$ & $\begin{array}{c}\text { 1993-94 } \\
\text { Slums }\end{array}$ \\
\hline \multicolumn{9}{|l|}{ Food items } \\
\hline Total cereals & 504 & 490 & 468 & 320.9 & 316 & 416 & 250.1 & 380.6 \\
\hline Wheat & & & & 273.8 & & & 216.4 & \\
\hline Rice & & & & 3.2 & & & 31.7 & \\
\hline Millet & & & & 43.9 & & & 2.0 & \\
\hline Pulses & 36 & 32 & 27.3 & 13.6 & 57 & 33 & 46.2 & 27 \\
\hline Leafy vegetables & 8 & 11 & 8 & 16 & 21 & 11 & 16.2 & 16 \\
\hline Other vegetables & 51 & 49 & 43 & & 113 & 40 & & 47 \\
\hline Roots and tubers & 48 & 50 & 35 & 45.2 & 82 & 70 & 78.4 & 51 \\
\hline Fruits & & & 21.2 & 19.2 & 124 & 26 & 73.6 & 26 \\
\hline Milk \& milk products & 100 & 96 & 85 & 60 & 424 & 42 & 303 & 75 \\
\hline Fats \& oils & 12 & 13 & 9 & 15.7 & 46 & 13 & 26.2 & 17 \\
\hline Sugars \& jaggery & 23 & 29 & 20 & 31.2 & 43.4 & 20 & 24.4 & 22 \\
\hline Flesh foods & & & 4.8 & 1.3 & 19 & 9 & 21.5 & 21 \\
\hline Fish & & & 16.6 & & 12 & 10 & & 22 \\
\hline Nuts \& oil seeds & & & 78.2 & & 21 & 9 & & 21 \\
\hline \multicolumn{9}{|l|}{ Nutrients } \\
\hline Protein (g) & 59 & 59 & 53 & 73.1 & 73.1 & 53.4 & 61 & 36.6 \\
\hline Carbohydrates (g) & & & & 347 & & & 282 & \\
\hline Fats (g) & & & & 63.1 & & & 61.4 & \\
\hline Fibre (g) & & & & 8.7 & & & 8.7 & \\
\hline Energy (kcal) & 2340 & 2283 & 2136 & 2249 & 2603 & 2008 & 1924 & 1915 \\
\hline
\end{tabular}

Source: National Nutrition Monitoring Bureau surveys, National Institute of Nutrition, Hyderabad, India.

availability of food and are also accompanied by qualitative changes in the diet. Food balance data from the Food and Agriculture Organization (FAO) show that the change in energy intake in Asian countries has been small, but there have been large changes in consumption of animal products, sugars and fats. The net effect has been a marked shift in the diet with energy from fat (both animal and vegetable) increasing each year. Data from India show that higher-income groups consumed a diet with $32 \%$ of the energy from fat while the lower-income groups consumed only $17 \%$ energy from fat. More recent dietary surveys in Delhi also confirm that the upperincome groups in urban India currently consume higher levels of energy from fat as compared with the urban poor or rural populations.

\section{Trends and patterns in food consumption in India}

There have been many nationally representative surveys on diet, nutrition and food consumption patterns in India since the 1970s. They include:

1. National Nutrition Monitoring Bureau (NNMB) surveys of diet and nutrition on a continuous basis in 10 states in India since 1971. One some occasions these NNMB surveys have been linked with the National Sample Survey Organisation (NSSO) and the National Council of Applied Economic Research (NCAER);

2. National Family Health Survey (NFHS) conducted by the Ministry of Health and Family Welfare and coordinated by the International Institute for Population
Sciences, Bombay. The NFHS surveys cover 24 states and provide anthropometric data on women aged 15 to 49 years;

3. District Nutrition Profiles survey organised by the Food and Nutrition Board, Department of Women and Child Development, Government of India. The data from several of these surveys have been collated and are summarised below.

India was progressing towards adequacy in calorie intakes during the 1970s and up to the early 1980s that were well documented by the NNMB and other surveys. They showed a gradual improvement in caloric intake per head, typified by an increase in consumption of cereal grains, while the intake of most other food items such as milk, oil, sugar, etc. remained largely unchanged. However, many of these surveys revealed disparities in the intakes of most foods between rural and urban populations and between different socio-economic groups. Comparison of food consumption patterns shows a gradual reduction in cereal grain consumption between 1975 and 1995 (Table 5) that has not affected the average energy intake. This is largely the result of a progressive increase in the intake of protein, and probably fats. The latter is due to a phenomenal increase in the consumption of milk and milk products and an increase in the intake of animal products (designated flesh foods) and fats and oils. The production of pulses and legumes is a concern and consequently their cost and consumption have fallen dramatically. This is a cause for much concern 
Table 6 Rural-urban differences in consumption of food items ( $\mathrm{g}$ per consumption unit (CU) per day) and nutrients in India based on a recent survey covering 187 Districts in 18 States ( $n=142220$ rural and 35621 urban adults)

\begin{tabular}{lrr} 
& \multicolumn{2}{c}{$\begin{array}{c}\text { Consumption of food items } \\
\text { (g per CU per day) }\end{array}$} \\
\cline { 2 - 3 } & \multicolumn{1}{c}{1998} & 1998 \\
\cline { 2 - 3 } & Rural & Urban \\
\hline Food items & & \\
Total cereals & 488.1 & 419.5 \\
Pulses \& legumes & 32.5 & 54.9 \\
Leafy vegetables & 31.8 & 23.4 \\
Other vegetables & 70.2 & 75.1 \\
Roots and tubers & 98.6 & 126.6 \\
Fruits & 14.7 & 37.6 \\
Milk \& milk products & 125.9 & 142.5 \\
Flesh foods & 22.0 & 19.0 \\
Fats \& oils & 14.3 & 21.2 \\
Sugars \& jaggery & 20.2 & 21.9 \\
Nutrients & & \\
Energy (kcal) & 2321.0 & 2259.0 \\
Protein (g) & 70.0 & 70.0 \\
Fats (g) & 31.3 & 39.5 \\
\hline
\end{tabular}

Source: District Nutrition Profiles Survey 1998, Ministry of Human Resources, Government of India.

since pulses and legumes are a very important source of vegetable proteins in the habitual Indian diet. Trends in the changes in consumption of urban populations are not readily available, although the surveys conducted between the late 1970s and the 1990s show wide differences between the socio-economic strata in an urban environment (Table 5). One would have expected these disparities to have widened further over the years, although they do not seem to be evident from the data. Table 6 presents recent data from the District Nutrition Profiles survey ${ }^{17}$, which shows differences particularly in the intakes of vegetables and fruits and fats and oils between urban and rural populations. The National Family Health Survey ${ }^{22}$ provides information on the consumption of specific and selected foods once a week at least and demonstrates, for instance, that the percentage of women consuming meat/chicken/fish once a week is higher in urban than rural locations and not related to standard of living index or educational status except for the illiterate group.

\section{Intake offat in the diet}

It has been well documented that the intake of fat in the diet has been increasing in developing countries based on the food balance analyses carried out by the FAO. When the dietary energy supply increases, the fat calorie ratio (i.e. the contribution of fat to energy) increases mainly due to the increase in consumption of animal products. The fat calorie ratio is $10 \%$ at $2000 \mathrm{kcal}$, but it is $41 \%$ at $3600 \mathrm{kcal}$, with the contribution from animal fats increasing from $29 \%$ to $64 \%$. Food balance data from the FAO show India at the bottom of the group of countries with a fat calorie ratio
Table 7 Dietary fat intake by urban and rural socio-economic group in India

\begin{tabular}{lrrrr}
\hline & \multicolumn{3}{c}{ Fat intake $\left(\mathrm{gday}^{-1}\right)$} & \\
\cline { 2 - 3 } Income group & Visible & Invisible & Total & Fat as \% of energy \\
\hline Urban & & & & \\
$\quad$ High & 46 & 49.7 & 95.7 & 33.1 \\
$\quad$ Middle & 35 & 36.5 & 71.5 & 27.2 \\
Low & 22 & 29.9 & 51.9 & 21.0 \\
Industrial labour & 23 & 30.0 & 53.0 & 21.3 \\
$\quad$ Slum dweller & 13 & 24.2 & 37.2 & 16.7 \\
Rural* & & & & \\
$>150$ & 25 & 27.4 & 53.4 & 18.5 \\
90-150 & 17 & 25.6 & 42.6 & 14.8 \\
$60-90$ & 13 & 22.8 & 35.8 & 13.3 \\
$30-60$ & 9 & 20.3 & 28.3 & 11.0 \\
$<30$ & 5 & 18.0 & 23.0 & 9.5 \\
$\quad$ Average & 9 & 25.6 & 34.6 & 13.7 \\
\hline
\end{tabular}

Source: Computed from dietary intake data of the National Nutrition Monitoring Bureau, 1987.

${ }^{*}$ Rural income in rupees per month.

over $15 \%(15.3 \%)$ with a total fat intake at $37.8 \mathrm{~g}$ per day and a $27.5 \%$ animal fat to total fat ratio ${ }^{25}$. Trends based on food balance sheet data show that the per capita supply of animal products has increased from $7.0 \mathrm{~g}$ in 1965 to $12.9 \mathrm{~g}$ in 1999, thus contributing almost twice the energy content (increased from 104 to $192 \mathrm{kcal}$ per capita per day).

Estimates from the NNMB helped assess the fat intake from Indian dietary components. It has now been recognised that components of the Indian diet such as cereals, pulses, tubers and vegetables have 'invisible fat', in addition to the obviously visible fats consumed in the daily diet, which exists within the integral part of the grain or food. It has been computed that 10-15\% of the daily energy in the diet can come from this invisible component and this level is adequate to meet the essential fatty acid requirements for both linoleic acid and alpha linolenic acid. Dietary fat intake, based on household surveys, suggests that the visible fat in poor rural diets is largely vegetable-based with negligible animal fats. The differences in the dietary fat intake between rural and urban and between lower and higher socio-economic groups are largely due to large differences in the intakes of visible fats, except in the highest income group (Table 7) where much of it is from animal sources, with the invisible fat intake being similar among these groups ${ }^{26}$. Computations also suggest that $25 \%$ of all available fat is consumed by the rural population, while $40 \%$ of all edible fat available in India is being consumed by $5 \%$ of the total population (i.e. $20 \%$ of the urban population that constitutes the 'urban-rich').

\section{Consumption of fruits and vegetables and dietary fibre}

Most horticultural products are generally good sources of vitamins, minerals and fibre as well as bioactive compounds like phytochemicals. The area under cultivation and the horticultural outputs have increased dramatically over the years. India has a prominent share 
in the global production of fruits and vegetables ${ }^{27}$. However, much of this does not seem to be reflected in increases in the consumption of fruits and vegetables perhaps largely the result of their production as cash crops for export and sale. This can lead to a considerable loss of soil and micronutrients that are not beneficial to the local population. However, economic development seems to lead to improvements in intakes of legumes and vegetables (as well as animal products) and these changes may be beneficial. But these changes with socio-economic status are also often associated with reduced intakes of coarse cereal grains and increased reliance on highly polished varieties that may reduce the intakes of dietary fibre.

\section{Changes in physical activity patterns}

Physical activity has declined in the industrialised world as a result of increasing mechanisation ${ }^{28}$. Time in a day or week dedicated to paid work has declined in several countries since the early 1960 s as a result of shorter work shifts, shorter weeks and longer vacations. The decline in time dedicated to productive work has been accompanied by a reduction in energy spent at work resulting from increased mechanisation of occupational work. Concurrent to this decrease in the energy expenditure in occupational activities, increased urbanisation, universal use of motor cars, mechanisation of most manual jobs outside the occupational sphere and increasing leisure time have aggravated this trend. Increased leisure time is most often dedicated to sedentary activities like television viewing, thus altering the structure of leisure time and encroaching on time normally allocated to other activities including weekday sleep. A similar phenomenon is occurring in developing societies like India and there is need to obtain data on levels of physical activity and patterns of activity in both rural and urban settings.

\section{Conclusions}

This review has attempted to look at some of the important determinants that characterise the nutrition and development transition that is occurring in a country like India: the demographic and epidemiological transition, the forces of internal migration and urbanisation, the changes in food consumption patterns and physical activity patterns that in turn are contributing to increasing sedentarianism, an epidemic of obesity and of other NCDs. India is a country of stark inequalities in income and health risks. The wide variations in the latter are largely attributable to the fact that epidemiological transition marks a stage in the economic growth of the country during which the vast majority of the population gains reliable access to the basic necessities of life, including adequate food and nutrition. Once the threshold standard of living is attained, no further improvement in life expectancy or health is readily apparent. What then becomes obvious is that the disparities in income influence health: the larger the degree of inequality (i.e. relative poverty), the lower the life expectancy of the population ${ }^{29}$. It has previously been demonstrated that chronic disease first affects the affluent classes within a population and then percolates through to other social classes; a feature seen in industrialised societies some decades ago but now manifest in rapidly developing countries. It will not be long before similar reversals in the risk of chronic disease are apparent in the lower socio-economic groups of India, particularly since societies in rapid transition are likely to manifest quite marked polarisation in income during the developmental process.

There are several other factors likely to contribute to the emerging burden of chronic diseases in India. Pollution of food sources by pesticides, chemical fertilisers and toxic contaminants is common in rapidly industrialising societies, particularly when regulatory bodies are lax, enforcement agencies are weak, public awareness is poor and consumer organisations ineffective. Globalisation of trade encourages cash crops for export and the resultant movement of important micronutrients, which are now not available to the local population, and at the same time promotes increased vulnerability with agricultural production subject to the pressures of global free trade and competition. Opening the economies of the developing world to the free market compounds the situation. This results in the inculcation of imbalanced and calorically excessive Western-type diets existing globally, together with the widening of socio-economic differentials and inequalities in the society. Changes in lifestyles will further fuel this, as exemplified by the increasing level of smoking that is vigorously encouraged by the multinational tobacco industry among the young, to compensate for reduced sales in countries in the West. It is estimated that 50-60\% of adult males in developing countries are regular smokers, while the prevalence of smoking and related morbidity and mortality is declining in the industrialised West. Current trends indicate that an epidemic of smokingrelated mortality is inevitable ${ }^{30}$.

Free markets and the globalisation of economies are not merely integrating trade, investment and financial markets, they are also integrating consumer markets around the world. It is accelerating the trends in conspicuous consumption, competitive spending and rising standards. Simultaneously, it is creating new inequalities, increasing environmental damage and creating new challenges for protecting consumer rights. The severest environmental damage is concentrated in the poorest regions affecting the poorest people. They are more exposed to fumes and polluted rivers and the use of leaded petrol is crippling human health. Poverty and environmental degradation are thus caught in a downward spiral and will increase exposure to carcinogens and other toxins. Protecting consumer rights becomes a very complex challenge and there is an increased risk of exposure to deleterious 
chemicals that affect human health. Economic development thus contributes to increasing inequalities and exposure to factors that are harmful to health and may thus contribute to increasing NCD risk in developing societies in rapid developmental transition, like India.

\section{References}

1 Murray CJL, Lopez AD. Global Comparative Assessments in the Health Sector. Geneva: World Health Organization, 1994.

2 World Health Organization (WHO). Global Strategy for the Prevention and Control of Non-communicable Diseases. Geneva: WHO, 2000.

3 Shetty PS. Diet and life-style and chronic non-communicable diseases: what determines the epidemic in developing societies? In: Krishnaswami K, ed. Nutrition Research: Current Scenario and Future Trends. New Delhi: Oxford \& IBH Publishing Co., 2000; 153-67.

4 UNDP India. Demographic Transition in India 1998 [Online]. Available at www.undp.org.in/report/preidf 98. Accessed 3 August 2001.

5 Registrar General of India. Census of India, 1991. New Delhi: Registrar General of India, 1998.

6 Omran AR. The epidemiological transition. A theory of the epidemiology of population change. Milbank Q. 1971; 49: 509-38.

7 Ross R. Atherosclerosis: an inflammatory disease. N. Engl. J. Med. 1999; 340: 115-26.

8 Yudkin JS, Yajnik CS, Mohamed Ali V, Bulmer K. High levels of circulating proinflammatory cytokines and leptin in urban, but not rural, Indians. A potential explanation for increased risk of diabetes and coronary heart disease. Diabetes Care 1999; 22: 363-4.

9 McKeigue PM. Cardiovascular disease and diabetes in migrants - interactions between nutritional changes and genetic background. In: Shetty PS, McPherson K, eds. Diet, Nutrition and Chronic Disease: Lessons from Contrasting Worlds. London: John Wiley \& Sons, 1997; 59-70.

10 McKeigue PM, Sevak L. Coronary Heart Disease in South Asian Communities: A Manual for Health Promotion. London: Health Education Authority, 1994.

11 Ramachandran A. Epidemiology of non insulin dependant diabetes mellitus in India. In: Shetty PS, Gopalan C, eds. Diet, Nutrition and Chronic Disease: An Asian Perspective. London: Smith Gordon, 1998; 38-41.

12 Chadha SL, Gopinath N, Shekawat S. Urban-rural differences in the prevalence of coronary heart disease and its risk factors in Delhi. Bull. World Health Org. 1997; 75: 31-8.

13 Singh RB, Sharma JP, Rastogi V, Raghuvanshi RS, Moshiri M, Verma SP, Janus ED. Prevalence of coronary artery disease and coronary risk factors in rural and urban populations of north India. Eur. Heart J. 1997; 18: 1728-35.
14 Gopalan C. Diet related non-communicable diseases in South and South East Asia. In: Shetty PS, McPherson K, eds. Diet, Nutrition and Chronic Disease: Lessons from Contrasting Worlds. London: John Wiley \& Sons, 1997; 10-23.

15 World Health Organization (WHO). Obesity: Preventing and Managing the Global Epidemic. Report of a WHO consultation. WHO Technical Report Series No. 894. Geneva: WHO, 2000.

16 Popkin BM, Richards MK, Monteiro CA. Stunting is associated in children of four nations that are undergoing nutrition transition. J. Nutr. 1996; 126: 3009-16.

17 Government of India. India Nutrition Profile. New Delhi: Department of Women and Child Development, Ministry of Human Resources, Government of India, 1998.

18 Dhurandhar NV, Kulkarni PR. Prevalence of obesity in Bomaby. Int.J. Obes. Relat. Metab. Disord. 1992; 16: 367-75.

19 Gopinath N, Chadha SL, Jain P, Shekawat S, Tandon R. An epidemiological study of obesity in adults in the urban population of Delhi. J. Assoc. Physicians India 1994; 42: $212-5$.

20 Zargar AM, Masoodi SR, Laway BA, Khan AK, Wani AI, Bashir MI, Akthar S. Prevalence of obesity in adults - an epidemiological study from Kashmir valley of Indian subcontinent. J. Assoc. Physicians India 2000; 48: 1170-4.

21 Gopalan C. Obesity in the urban middle class. NFI Bull. 1998; 19: 1-4.

22 National Family Health Survey. India Main Report, 1991. Chapter 7: Nutrition and the prevalence of anaemia [Online]. Accessed 31 August 2001.

23 Dudeja V, Misra A, Pandey RM, Devina G, Kumar G, Vikram NK. BMI does not accurately predict overweight in Asians in northern India. Br. J. Nutr. 2001; 86: 105-12.

24 Yajnik CS. The insulin resistance epidemic in India: fetal origins, later lifestyle, or both? Nutr. Rev. 2001; 59: 1-9.

25 Food and Agriculture Organization (FAO)/World Health Organization (WHO). Fats and Oils in Human Nutrition. Report of a joint expert consultation. FAO Food \& Nutrition Papers, Vol. 57. Rome: FAO, 1994; 1-147.

26 Ghafoorunisa. Fats in Indian diets. NFI Bull. 1989; 10: 1-5.

27 Kaul GL. Fruit and vegetable production in India. NFI Bull. 1998; 19: 5-8.

28 Ferro-Luzzi A, Martino L. Obesity and physical activity. In: The Origins and Consequences of Obesity. Ciba Foundation Symposium, Vol. 201. Chichester: John Wiley \& Sons, 1996; 228-46.

29 Wilkinson RG. Mortality and distribution of income. Low relative income affects mortality. Br. Med. J. 1998; 316: 1611-2.

30 Peto R, Lopez AD. Worldwide mortality from current smoking pattern. In: Durston B, Jamrozik K, eds. Tobacco and Health 1990: The Global War. Perth: Health Department of Western Australia, 1990; 66-8. 